\title{
Doğum Eyleminde Tamamlayıcı ve Alternatif Bir Yöntem Olan Homeopati Kullanımı
}

\author{
Homeopathy as A Complementary and Alternative Medicine for Labour
}

\author{
Halime Esra PARTOVI MERAN ${ }^{1}$, Gülay RATHFISCH ${ }^{2}$
}

İletişim/Correspondence: Halime Esra PARTOVİ MERAN Adres/Adress: Selçuk Üniversitesi Sağlık Bilimleri Fakültesi, Doğum ve Kadın
Hastalıkları AD., Akademi Mah. Yeni İstanbul Cad. Alaeddin Keykubat Kampüsü 42250, Selçuklu/ Konya Tel:0332 2233519
Fax: 03322400056 E-mail: esrakal87@hotmail.com

$\ddot{O} Z$

Son zamanlarda doğum sürecinde; kontraksiyonların düzenlenmesi, doğum ă̆rısının azalttlmasl ve posterior prezantasyonların düzeltilmesi gibi durumlarda doğum eyleminin doğallı̆ııı en az düzeyde etkileyen homeopatinin uygulanması tavsiye edilmektedir. Homeopati ile vücudun doğal iyileşme süreci başlatılmaktadır. Homeopati, doğum eylemi dlşında gebelikteki fizyolojik yakınmaların giderilmesinde ve doğum sonu dönemde ise kanama ve enfeksiyon durumlarının tedavisinde kullanılmaktadır. Homeopatinin doğumda kullanımının güvenirliği konusunda bilimsel kanıtlar yetersiz olduğundan dolayı homeopatinin geleneksel bilgilerden daha çok kanıt temelli sonuçlar doğrultusunda uygulanması ve bu konuda multidisipliner bir yaklaşımın olması gerekmektedir. Sonuç olarak bu derleme; tamamlayıcı ve alternatif bir yöntem olarak doğumda homeopati uygulamasının literatür doğrultusunda incelenmesi amacıyla yapılmıştır.

Anahtar Kelimeler: Homeopati, doğum, tamamlayıcı ve alternatif yöntemler.

\section{ABSTRACT}

Recently on labour; in situations such as regulation of contractions, reduction of labour pain and posterior presentations, the homeophaty application that effects the naturalness of labour in minimum level is recommended. Homeopathy can be used to stimulate the body's natural healing ability. Homeopathy is used forin the treatment physiologically semptoms during pregnancy and postpartum hemorrhage and infection exclusive of labour. The scientific evidence is insufficient about the reliability of homeopathy on labour. Rather than the traditional information, homeopathy should be implemented accordance with evidence-based results and this issue should be a multidisciplinary approach. This review was condcuted to investigate the homeopathy as a complementary and alternative medicine for labour in accordance with the literature. Keywords: Homeopathy, labour, complementary and alternative methods.

\section{GíRiş}

Doğum eylemi doğal bir süreç olmasına karşın, bazen süreçle ilgili sorunlar ortaya çıkmaktadır. Doğum sürecinde ortaya çıkan sorunlar için uygulanan farmakolojik müdahaleler doğumu doğal bir süreç olmaktan çıkarmakta, çoğu kez hoş olmayan doğum serüvenlerine yol açmaktadır. Bu süreçte doğumun doğallığını en az düzeyde etkileyen tamamlayıcı ve alternatif yöntemlerin kullanılması tavsiye edilmektedir. Bu yöntemlerden en çok bilineni homeopatidir. Homeopati 18. yy'dan günümüze kadar Avrupa ve Hindistan'da yaygın olarak kullanılan ve eğitimli ebe-

${ }^{1}$ Arş. Gör. Selçuk Üniversitesi Sağlık Bilimleri Fakültesi Hemşirelik Bölümü, Konya/ TURKEY, ${ }^{2}$ Doç. Dr. İstanbul Üniversitesi Florence Nightingale Hemşirelik Fakültesi, İstanbul/ TURKEY

Yazının gönderilme tarihi: 12.01.2015

Yazının basım için kabul tarihi: 01.09.2016

doi: 10.17672/fnhd.93514 
hemşireler tarafindan gebelik, doğum ve doğum sonu dönemde uygulanan bir yöntemdir (Baxter ve Perrin 2006; Foxell 2013; Geraghty 2002; Hall, McKenna ve Griffiths 2012; Idarius 1999; Smith 2003; Steen ve Calvert 2007).

Homeopatinin temeli; en seyreltik (genellikle bitkilerden elde edilen ana maddenin 10 ya da $100 \mathrm{kez}$ seyreltilmesi) homeopatik maddelerle "benzeri ile tedavi etme" mantığına dayanmaktadır. Homeopati ile vücudun doğal iyileşme ve semptomlarla mücadele etme süreci başlatılmaktadır (Geraghty 2002; Idarius 1999; Smith 2003). Gebelik (genellikle gastrointestinal sorunlarda), doğum (kontraksiyonların düzenlenmesi, ağr1, posterior prezentasyonlar gibi durumlarda) ve doğum sonu dönemde (atoni sonucu kanama ve enfeksiyon gibi durumlarda) birçok homeopatik madde kullanılmaktadır (Geraghty 2002; Idarius 1999; Smith 2003; Steen ve Calvert 2007). Bu maddelerin en çok bilinenleri; caulophyllum, cimicifuga, pulsatilla, kali carbonicum, aconite, arnica, hypericum, chammomilla, staphisagria ve carboveg olarak siralanabilmektedir (Foxell 2013; Geraghty 2002; Idarius 1999).

Homeopatinin doğumda kullanımı ile ilgili cochrane veri tabanında tek bir sistematik araştırma sonucu yer almaktadır. Bu çalışma, son trimesterdeki 133 kadını kapsayan randomize kontrollü iki araştırma sonucundan oluşmaktadır (Smith 2003). Nitekim bu araştırma sonuçları da doğumda homeopatinin kullanılması konusunda yeterli kanıt sağlayamamaktadır (Hall ve ark. 2012; Smith 2003).

Bu derleme, tamamlayıcı ve alternatif bir yöntem olarak doğumda homeopati uygulamasının literatür doğrultusunda incelenmesi amacıyla yapılmıştır.

\section{Homeopatinin Tanımı ve Tarihçesi}

Homeopati; en seyreltik (genellikle bitkilerden elde edilen ana maddenin 10 ya da $100 \mathrm{kez}$ seyreltilmesi) homeopatik maddelerle sağlık sorunlarını "benzeri ile tedavi etme" yaklaşımıdır. Homeopati; bireyde mevcut hastalığın semptomlarına benzer semptomlar yapan seyreltik homeopatik ilaçların bireye verilmesiyle vücudun doğal iyileşme sürecinin başlatıldığ doğal bir tedavi yöntemidir (Heirs ve Dean 2007; Smith 2003).

Homeopatinin kelime kökeni Yunanca'dan gelmektedir. "Homoios-benzer" ve "pathos-acı çekmek" anlamındadır. Homeopati felsefesinin kökeninin Hipokrat'a kadar dayandığı belirtilse de temel felsefenin eski M1sırlı bilim adamlarına kadar uzandığı belirtilmektedir. 18. yy'da Alman Doktor Samuel Hahnemann "benzer acı çekmek" kavramı temelinde homeopati prensibini bulmuştur. Samuel Hahnemann, homeopatiyi "benzeri ile tedavi etme" temel prensibi doğrultusunda geliştirmiştir (Geraghty 2002; Merrell ve Shalts 2002; Tedesco ve Cicchetti 2001; The Society of Homeopath 2014). Hahnemann, homeopatik tedavi ile ilgili ilk ça1ş̧masını sıtma üzerinde yapmıştır. Hahnemann, sağlıklı bir kişide sıtma semptomları yapan Cinchona'dan (kınakına ağacı) elde ettiği seyreltik çözeltinin, sıtmalı bir hastada iyileştirici etkisinin olduğu gözlemlemiştir. Bunun sonucu olarak, homeopatik tedavinin ilk adımı başlamıştır (Idarius 1999; Geraghty 2002).

Hahnemann'dan sonra homeopati uygulamaları hızla yaygınlaşmaya başlamıştır. İlk olarak 1844’te Amerika'da “Amerikan Homeopati Enstitüsü”, Britanya'da "İngiliz Homeopati Birliği” kurulmuş, homeopatik hastaneler ve homeopatik tıp okulları açılmıştır. Son yıllarda ise homeopati ayrı bir uzmanlık dalı olarak Meksika, İngiltere, Fransa, Brezilya, Arjantin ve Hindistan'da yaygın olarak kullanılan bir yöntem olmuştur (Idarius 1999; Geraghty 2002). Homeopatik uygulamaların yasal olarak tanınmasi; ilk olarak İngiltere'de 1950'de, Romanya'da 1981'de, Macaristan ve Letonya'da 1997'de, Almanya'da 1998'de, Belçika'da 1999'da, Portekiz'de 2003 'te, Bulgaristan'ta 2005'te ve Slovenya'da 2007'de olmuştur (ECH 2014).

\section{Homeopati ile İlgili Araştırmalar ve Kullanım Alanları}

Homeopatinin kullanımı ve etkinliği ile ilgili araştırmalar 19. yy başlarında hız kazanmıştır (Geraghty 2002). Homeopati kullanımına ilişkin İngiltere'de yapılmış araştırma sonuçlarına göre; yetişkinlerin \%1,9'unda (Thomas ve Coleman 2004) ve 16 yaş 
altındaki çocukların \%11'inde (Simpson ve Roman 2001) homeopatik yöntemlerin kullanıldı̆̆ bildirilmektedir. Homeopati, Avrupa ve Amerika'da; solunum sistemi ve gastrointestinal sistemde yaygın olarak görülen hastalıkların, gebelik, doğum ve doğum sonu dönemde sık yaşanan sorunların ve çocuklarda sık görülen sağlık sorunlarının (enürezis gibi) tedavisinde sıklıkla kullanılan alternatif ve tamamlayıcı bir tedavi yöntemi olmuştur (Geraghty 2002).

Homeopati uygulamasının yaygın olarak görülen; dikkat eksikliği/hiperaktivite bozukluğu (Heirs ve Dean 2007), irritabl bağırsak sendromu (Peckham ve ark. 2013), kronik astım (McCarney, Linde ve Lasserson 2004), kemoterapiye bağlı gelişen stomatit (Kassab, Cummings, Berkovitz, VanHaselen ve Fisher 2009), çocuklarda enürezis (Huang, Shu, Huang ve Cheuk 2011) ve diyare (Jacobs, Jimenez, Gloyd, Gale ve Crothers 1994) gibi hastalıkların tedavisinde yararlı olduğu kanıt temelli çalışmalarda gösterilmiştir. Fakat bu çalışmalarda metodoloji ile ilgili sınırlılıklar nedeniyle homeopatinin etkin bir tedavi olduğu ile ilgili veriler sınırlıdır (Heirs ve Dean 2007; Huang ve ark. 2011; Jacobs ve ark. 1994; Kassab ve ark. 2009; McCarney ve ark. 2004; Peckham ve ark. 2013).

Homeopati uygulaması ebe ve hemşireler tarafından gebelik döneminde sık görülen; abdominal ağrı, sırt ağrısı, karpal tünel sendromu, konstipasyon, kas krampları, diyare, baş dönmesi ve bayılma, sık idrara çıkma, gestasyonel hipertansiyon, hemoroid, mide yanması, uyku sorunları, siyatik ağrı, cinsel sorunlar, bacak ve vulvadaki varikoz venler, bulantı, kusma, düşük tehdidi, vajinal kanama ve akıntı sorununun tedavisinde kullanılmaktadır (Geraghty 2002).

Homeopatinin doğumda kullanımı ile ilgili cochrane veri tabanında; son trimesterdeki 133 kadını kapsayan, randomize kontrollü iki araştırma sonucunu içeren tek bir sistematik derleme yer almaktadır (Smith 2003). $\mathrm{Bu}$ araştırmalarda Caulophyllum (Mavi Cohosh)'dan elde edilen homeopatik ilacın, doğum eylemini başlatmada etkili olmadığı sonucuna varılmıştır. Bu durumun araştırmaların metodolojisi ile ilgili yetersizlikten ve homeopatik tedavinin bireye özel olarak uygulanmasından kaynaklanabileceği düşünülmektedir. Nitekim bu araştırma sonuçları da, doğumda homeopatinin kullanılması konusunda yeterli kanıt sağlamamaktadır (Hall ve ark. 2012; Smith 2003).

Homeopati uygulaması ebe ve hemşireler tarafindan postpartum dönemde; ağrının azaltılması, meme ve emzirme sorunları, ürinasyonla ilgili sorunlar, depresyon, subinvolisyon ve anormal loşianın tedavisinde kullanılmaktadır (Geraghty 2002).

Homeopati uygulaması ebe ve hemşireler tarafindan ayrıca bebeklerde sık görülen; kolik ağrı, konstipasyon ve diyare, uyku sorunları, oral ve rektal kandida, yenidoğan sarılığı ve deri tahrişlerinin tedavisinde kullanılmaktadır (Geraghty 2002).

\section{Homeopatik İlaçlar}

Homeopatik ilaçlar, genellikle bitkilerden ya da minerallerden (altın ve kum gibi) elde edilmektedir. Homeopatik ilaçların birey üzerinde etkili olabilmesi için aşamalı ve tekrarlayan seyreltme işlemlerine tabi tutulması gerekmektedir. Homeopatik bir ilaç $10 \mathrm{kez}$ ya da $100 \mathrm{kez}$ seyreltilebilmekte ve seyreltilme oranları rakamlarla ilaç etiketi üzerinde gösterilmektedir. Örneğin homeopatik ilaç isminin yanında 6 yazmas1, homeopatik ilacın 6 kez seyreltilme işleminden geçtiğini göstermektedir (Geraghty 2002; Kömürcü ve Berkiten-Ergin 2008; Merrell ve Shalts 2002). Homeopatik ilaçların seyreltilmiş formları ana maddeye göre daha etkili olup daha az yan etkiye neden olmaktadır. Homeopatik ilaçlar seyreltilme işlemi sırasında ana maddedeki moleküllerin çok azını bazen de hiçbirini içermediği, ayrıca biofiziksel mekanizmalar üzerindeki etkisinin net olmadığı bildirilmektedir. $\mathrm{Bu}$ nedenle çoğu bilim adamı tarafından homeopatik ilaçların klinik etkilerinin plasebo etkisine yol açabileceği savunulmaktadır (Smith 2003). Homeopatik ilaçlar; yaş, cinsiyet ve duygu durumu gibi kişisel özellikler temelinde bireydeki semptom ve hastalık tanılarına göre kullanılmaktadır. Homeopati uzmanı tarafindan, semptom ve hastalık tanılarına göre bireye özel homeopatik ilaçlar reçete edilmektedir (Geraghty 2002). 
Günümüzde homeopatik ilaçlar FDA (U.S. Food and Drug Administration) tarafından onaylanmış olarak homeopatik eczanelerde hazırlanmaktadır. Avrupa'daki birçok ülkede homeopatik ilaçlar reçetesiz olarak eczanelerde ve sağlıklı yaşam ürünlerini satan mağazalarda; toz, yumuşak tablet, sert tablet, granül, sakaroz ya da şeker drajeleri ve sıvı form şeklinde satılmaktadır (Geraghty 2002). Homeopatik ilaçlar pahalı olmayan, güvenilir ilaçlardır (Idarius 1999). Homeopatik ilaçların gebelikte ve doğumda kullanımının nadir olarak ciddi yan etkilere neden olduğu bildirilmektedir (Smith 2003).

\section{Doğum Eyleminde Homeopati Uygulamaları}

Doğum eyleminde farklı özelliklere sahip homeopatik ilaçlar kullanılmaktadır. Aşağıda doğum eyleminde kullanılan homeopatik ilaçlar ve kullanım alanları ile ilgili bilgi verilmiştir. Ayrıca doğum eyleminde kullanılan homeopatik ilaçlar ve kullanım alanları özet olarak Tablo 1'de sunulmuştur.

Caulophyllum (Mavi Cohosh): Özellikle doğum ağrısının oluşmasında ve düzenlenmesinde (kısa, düzensiz ya da durmuş kontraksiyonlarda), acı veren, spazmodik, keskin, uterin ligamentlerde kramp tarzında ağrıya neden olan, kasıklara ve bele yansıyan doğum ağrısının hafifletilmesinde ya da giderilmesinde kullanılmaktadır. Ayrıca serviksin açılmayacak kadar rijit olduğu durumlarda kullanılmaktadır. Mekanizması tam olarak bilinmese de endojen oksitosin üretiminde etkili olduğu savunulmaktadır. (Geraghty 2002; Idarius 1999; Smith 2003).

Cimicifuga (Siyah Cohosh): Doğumun her aşamasında oluşan bel ağrısının giderilmesinde, doğum indüksiyonunda, servikal dilatasyonun sağlanmasında, uzamış ve zor doğum eyleminde ve doğum korkusunun giderilmesinde etkili olduğu bildirilmektedir. Ayrıca Cimicifuga, Caulophyllum ile birlikte postpartum kanamanın azaltılmasinda ve plasenta retansiyonlar1nın tedavisinde de kullanılmaktadır (Geraghty 2002; Idarius 1999; Martin 2001).

Pulsatilla: 36. haftasından gün almış, pelvise yerleşmemiş makat prezentasyondaki fetüsün pozisyonunun doğumdan önce baş prezentasyonuna getirilmesinde ve posterior prezentasyona bağlı gelişen bel ağrılar1nın giderilmesinde etkili olduğu bildirilmektedir. Ayrıca uterus kontraksiyonlarının kısa, zayıf olduğu ya da durduğu durumlarda ve travaydaki gebenin aşırı derecede halsiz, bulantı ve kusmanın aşırı olduğu durumlarda kullanıldığı bildirilmektedir. Pulsatilla, doğum sonu dönemde plasenta retansiyonuna bağlı gelişen postpartum kanamaların tedavisinde de kullanılmaktadır (Foxell 2013; Geraghty 2002; Idarius 1999).

Kali Carbonicum: Doğum eyleminin birinci evresinde olan bir gebede şiddetli bel ve sırt ağrılarının giderilmesinde ve posterior prezentasyonlarda bebeğin rotasyonunun sağlanmasında etkili olduğu bildirilmektedir (Geraghty 2002; Idarius 1999; Martin 2001).

Aconite: Aşırı korkuya bağlı gelişen erken uterin kontraksiyonların azaltılmasında ve düşük tehdidinin giderilmesinde kullanılmaktadır. Uzamış ve zor doğum eyleminde doğum sırasında yaşanan anksiyete ve korkunun giderilmesinde ve yaşanan doğum ağrısının hafifletilmesinde etkili olduğu bildirilmektedir. Aconite ayrıca doğum sonu dönemde postpartum kanamaların azaltılmasında da kullanılabilmektedir (Foxell 2013; Geraghty 2002; Idarius 1999).

Arnica: Çok uzun süren travmatik doğumlarda; doğum ağrısının hafifletilmesinde kullanılmaktadır. Doğum sonu dönemde travmalara bağlı gelişen perineal bölgedeki yırtık ve ödeminin tedavisinde ve postpartum kanamanın azaltılmasında etkili olduğu bildirilmektedir. Ayrıca yorgunluğu azaltıcı etkisi olduğu için doğum öncesi ve doğum sonrası dönemde kullanılmaktadır (Foxell 2013; Geraghty 2002; Idarius 1999).

Hypericum: Özellikle doğum sonrası dönemde yaşanan bel ağrılarının, perineal yırtık ve epizyotomiye bağlı gelişen perineal ağrının giderilmesinde etkili olduğu bildirilmektedir (Foxell 2013; Geraghty 2002; Idarius 1999).

Chammomilla: Uzamış ve zor doğum eyleminde; doğum ağrısının hafifletilmesinde, bel ağrısının azaltılmasında ve yaşanan gerginlik ve anksiyetenin giderilmesinde kullanıldığ 1 bildirilmektedir. (Foxell 2013; Geraghty 2002; Idarius 1999). 
Tablo 1. Doğum Eyleminde Kullanılan Homeopatik İlaçlar ve Homeopatik İlaçların Kullanıldığı Durumlar

\begin{tabular}{|c|c|c|}
\hline $\begin{array}{l}\text { Doğum } \\
\text { Evrelerine Göre } \\
\text { Homeopati } \\
\text { Uygulaması }\end{array}$ & $\begin{array}{l}\text { Homeopati } \\
\text { Uygulaması } \\
\text { Gerektiren } \\
\text { Durumlar }\end{array}$ & $\begin{array}{l}\text { Homeopatik } \\
\text { İlaçlar }\end{array}$ \\
\hline \multirow{24}{*}{$\begin{array}{l}\text { Doğum } \\
\text { eyleminin } \\
\text { birinci ve ikinci } \\
\text { evresinde } \\
\text { homeopati } \\
\text { uygulamaları }\end{array}$} & \multirow{4}{*}{$\begin{array}{l}\text { Doğum } \\
\text { korkusunda }\end{array}$} & Aconite \\
\hline & & Chammomilla \\
\hline & & Staphisagria \\
\hline & & Cimicifuga \\
\hline & \multirow{6}{*}{$\begin{array}{l}\text { Doğum ă̆risının } \\
\text { hafifletilmesinde }\end{array}$} & Aconite \\
\hline & & Arnica \\
\hline & & Carboveg \\
\hline & & Caulophyllum \\
\hline & & Chammomilla \\
\hline & & Cimicifuga \\
\hline & \multirow{3}{*}{$\begin{array}{l}\text { Dŏ̆um } \\
\text { indüksiyonunda }\end{array}$} & Caulophyllum \\
\hline & & Cimicifuga \\
\hline & & Pulsatilla \\
\hline & $\begin{array}{l}\text { Doğumdan } \\
\text { önceki fetüsteki } \\
\text { prezentasyon } \\
\text { değişikliklerinde }\end{array}$ & Pulsatilla \\
\hline & \multirow{4}{*}{$\begin{array}{l}\text { Posterior } \\
\text { prezentasyonlarda } \\
\text { ve bu süreçte } \\
\text { oluşan bel } \\
\text { ağrılarında }\end{array}$} & Caulophyllum \\
\hline & & Chammomilla \\
\hline & & Kali Carbonicum \\
\hline & & Pulsatilla \\
\hline & \multirow{6}{*}{$\begin{array}{l}\text { Uzamış ve zor } \\
\text { doğum eyleminde }\end{array}$} & Caulophyllum \\
\hline & & Cimicifuga \\
\hline & & Aconite \\
\hline & & Caulophyllum \\
\hline & & Chammomilla \\
\hline & & Pulsatilla \\
\hline \multirow{12}{*}{$\begin{array}{l}\text { Doğumun } \\
\text { üçüncü ve } \\
\text { dördüncü } \\
\text { evresinde } \\
\text { homeopati } \\
\text { uygulamaları }\end{array}$} & \multirow{6}{*}{$\begin{array}{l}\text { Postpartum } \\
\text { kanamada }\end{array}$} & Aconite \\
\hline & & Carboveg \\
\hline & & Caulophyllum \\
\hline & & Arnica \\
\hline & & Cimicifuga \\
\hline & & Pulsatilla \\
\hline & \multirow{3}{*}{$\begin{array}{l}\text { Plasenta } \\
\text { retansiyonunda }\end{array}$} & Pulsatilla \\
\hline & & Caulophyllum \\
\hline & & Cimicifuga \\
\hline & \multirow{3}{*}{$\begin{array}{l}\text { Perineal yurtık ve } \\
\text { epizyotomilerde }\end{array}$} & Arnica \\
\hline & & Hypericum \\
\hline & & Staphysagria \\
\hline
\end{tabular}

Staphisagria: Gebede daha önce travmatik bir doğum deneyimine bağlı korku ve ajitasyon olduğu durumlarda, ayrıca müdahaleli (vakum, forseps gibi) doğumlarda gebeyi sakinleştirmek amacıyla kullanılabileceği bildirilmektedir. Ayrıca perineal yırtık ve epizyotomi tamirinde gebeyi rahatlatmak amaçli kullanılabilmektedir (Foxell 2013; Geraghty 2002; Idarius 1999).

Carboveg: Fetal distres durumlarında, doğum süreci ve sonrasında aşırı kanama, hava açlığı ve ağrının azaltılmasında kullanıldı $\breve{g}_{1}$ bildirilmektedir (Foxell 2013; Geraghty 2002; Idarius 1999).

\section{Dünya'da ve Türkiye'de Doğum Eyleminde Homeopati Uygulamalarının Durumu ve Homeopati Uygulamalarında Hemşirelerin Rolleri}

Avrupa ve Amerika'daki birçok ülkede homeopati uygulamalarının yasal olması, gebelik ve doğum sürecinde homeopati kullanımının gittikçe artmasına neden olmuştur. Homeopati uygulamalarındaki yasal süreç kapsamında homeopati uygulamaları; homeopati eğitimi almış hekimler, farmakologlar, doğal tedavi uzmanları, hemşireler ve ebeler tarafından yapılmaktadır (ECH 2014). Homeopati uygulamalarında ortak bir bakış açısı oluşturmak amacıyla; homeopati okullarının verdiği kurs ve sertifika programlar1n1 akredite etmek, eğitim ve uygulama standartlarını oluşturmak, etik kodları belirlenmek ve bilimsel gelişmeyi artırmak amacıyla Amerika ve Avrupa'da komisyonlar, dernekler ve komiteler kurulmuştur Bu bağlamda homeopati alanında ilk olarak 1978'de İngiltere'de "Homeopatlar Derneği" (The Society of Homeopaths), 1982'de "Kuzey Amerika Homeopatik Eğitim Akreditasyon Komisyonu" (The Accreditation Commission for Homeopathic Education in North America), 1991'de "Homeopatik Sertifikasyon Konseyi" (Council for Homeopathic Certification) ve 1992'de "Avrupa Homeopati Komitesi” (The European Committee for Homeopathy) kurulmuştur (ACHENA 2014; CHC 2014; ECH 2014; The Society of Homeopaths 2014). 
Homeopati alanındaki gelişmelerle eş zamanlı olarak hemşirelik ve ebelik uygulamalarında da homeopati yerini almıştır. 1982'de kurulan "Kuzey Amerika Homeopatik Eğitim Akreditasyon Komisyonu"nun ardından hemşirelik alanında homeopati uygulamalarıyla ilgili olarak 1984 yılında "Homeopatik Hemşireler Derneği”" kurulmuştur. "Homeopatik Hemşireler Derneği" kapsamında, homeopati okulları tarafindan verilen kurs programları, kurs programlarının etkinliği ve uygulamada yaşanan sorunlar tartışılmaktadır (HNA 2014). Hemşire ve ebelerin homeopatik ilaçları gebelik, doğum ve doğum sonu dönemde uygulayabilmeleri için homeopati okulları tarafindan verilen homeopati kurslarını tamamlamaları ve sertifikalarını almaları gerekmektedir (Baxter ve Perrin 2006; CHC 2014). Homeopati eğitimi sonucunda sertifika alabilmek için; 500 saatlik homeopati eğitimi ve 10 vaka üzerinde uzman denetiminde homeopati uygulamas1nın tamamlanması ve eğitim sonunda yapılan sınavın geçilmesi gerekmektedir (CHC 2014). Bu bağlamda Homeopati, Amerika ve Avrupa'da homeopati sertifikası almış eğitimli ebe-hemşireler tarafından gebelik, doğum ve doğum sonu dönemde yaygın olarak uygulanan bir tedavi yöntemi olmuştur (Baxter ve Perrin 2006; Foxell 2013; Geraghty 2002; Hall ve ark. 2012; Steen ve Calvert 2007). Kuzey Karolina'da yapılan bir araştırmada hemşire ve ebelerin \%30'undan fazlasının gebelikte homeopatinin kullanımını tavsiye ettikleri saptanmıştır (Allaire, Moos ve Wells 2000). Homeopati uygulaması kapsamında hemşirelerin rolleri; bireyin durumuna özgü olarak homeopatik ilaçların uygulanması, homeopatik ilaçları uygularken etik ilkelere (bireye zarar vermeme, yararlı olma gibi) uyulması, homeopatik uygulama sonucunda beklenen etkinin gözlenmesi, istenmeyen durumların önlenmesi için gerekli tedbirlerin alınması ve herhangi bir yan etki geliştiğinde gerekli müdahalelerin ve sağlık kurumuna sevk işlemlerinin yapılması olarak sıralanmaktadır (HNA 2014). Türkiye'de homeopati uygulamaları Avrupa ve Amerika'ya göre daha çok yenidir. Türkiye'de homeopatinin yaygınlaşması, homeopati uzmanı yetiştirmek, homeopati uygulamaları ve bu alanda araştırmalar yapmak amaciyla 2008 yılında "Homeopati
Derneği” kurulmuştur. Homeopati Derneği “Avrupa Homeopati Komitesi” standartları doğrultusunda kurslar düzenlemektedir. Homeopati kursu; 3 yıl boyunca her ayın 2 günü toplamda 400 saatlik teorik ders ve vaka çalışmalarını tamamlayacak şekilde verilmektedir. Kursa; tıp doktorları, diş hekimleri, veteriner hekimler, eczacılar, psikologlar ve hemşireler katılabilmektedir (Homeopati Derneği 2014).

Türkiye'de homeopati uygulamaları, "Geleneksel ve Tamamlayıcı Tıp Uygulamaları Yönetmeliği” ile yasal bir boyut kazanmıştır. Bu yönetmelik kapsamında homeopati uygulamalarının yalnızca Sağlık Bakanlığı tarafından yetkilendirilmiş ünite ve uygulama merkezlerinde yapılabileceği ve homeopati alanında "uygulama sertifikası" bulunan (Yurt dışından alınan sertifikaların Sağlık Bakanlığı tarafindan onaylanması gerekmektedir) hekim veya kendi alanında uygulama yapmak üzere diş hekimlerinin uygulama yapmaya yetkili olacağı belirtilmektedir. Uygulamaya yetkili personel yalnızca sertifikalı doktor ve diş hekimi olarak kısıtlanmıştır. Yani bu yönetmelik ile Türkiye'de hemşire ve ebelere homeopati uygulama yetkisi verilmemektedir. Bu yönetmelik kapsamında gebelik ve doğumda homeopati uygulamaları ile ilgili olarak yalnızca "infertilite" ve "doğum sancısı" ile ilgili homeopati uygulamalarına yer verilmiştir. Yönetmelik kapsamında homeopati eğitimi Sağlık Bakanlığınca yetkilendirilmiş merkezler tarafından verilir (T.C. Başbakanlık Mevzuatı Geliştirme ve Yayın Genel Müdürlüğü 2014). Klasik homeopati eğitimi; hekimler ve diş hekimleri için 220 saat teorik ders, 130 saat vaka ve süpervizyon çalışmalarını, klinik homeopati eğitimi ise 180 saat teorik ders, 170 saat vaka ve süpervizyon çalışmalarını içermektedir. Hekim ve diş hekimlerinin klasik homeopati veya klinik homeopati programlarından birini seçmek zorunda oldukları bildirilmektedir. Ayrıca yönetmelikte eczacıların; homeopatik ilaçların hazırlanışı ve homeopatik ilaçlara yönelik hastaları bilgilendirebilmeleri için klasik homeopati eğitimi kapsamında 170 saatlik teorik ders ve 40 saatlik vaka ve süpervizyon çalışmalarını tamamlamaları gerektiği belirtilmektedir. Eczacılara yönelik 
klinik homeopati eğitimi yapılmamaktadır (T.C. Sağlik Bakanlığı 2014).

\section{SONUÇ VE ÖNERILLER}

Yaklaşık olarak 200 yıllık bir geçmişe sahip olan homeopati; çeşitli hastalıkların, gebelik, doğum ve doğum sonu dönemde görülen sorunların tedavisinde yaygın olarak kullanılan tamamlayıcı ve alternatif bir yöntem olmuştur. Doğum eyleminde; kontraksiyonların düzenlenmesi, doğum ağrısının azaltılması ve posterior prezantasyonların düzeltilmesi gibi durumlarda doğal iyileşme sürecini başlattığ 1 için doğumun doğallığına daha az zarar veren homeopatik yöntemler kullanılmaktadır. Homeopatik ilaçların doğumda kullanımının güvenirliği konusunda bilimsel kanıtlar yetersizdir. Bu nedenle homeopatinin geleneksel bilgilerden daha çok kanıt temelli sonuçlar doğrultusunda, etik ve yasal prosedürler kapsamında multidisipliner bir yaklaşımda uygulanması gerekmektedir.

Dünya'da gelişmiş ülkelerde yasal prosedürler kapsamında uzun y1llardır uygulanan homeopati, ülkemizde yeni tanınan bir yöntemdir. Türkiye'de homeopati uygulamalarına yasal bir boyut kazandırmak için "Geleneksel ve Tamamlayıcı Tıp Uygulamaları Yönetmeliğii” hazırlanmıştır. Fakat bu yönetmelik kapsamında hemşire ve ebelere homeopati uygulama yetkisi verilmemiştir. Oysa uzun yıllardır homeopati Avrupa ve Amerika'daki birçok ülkede sertifikalı hemşire ve ebeler tarafından gebelik, doğum ve doğum sonu dönemde yaygın olarak kullanılmaktadır. Homeopati uygulama yetkisi ile hemşire ve ebeler bağımsız rollerini yerine getirmektedir. Gebelik, doğum ve doğum sonu dönemde homeopati uygulama yetkisi ile hemşire ve ebeler; bireyin durumuna özgü olarak homeopatik ilaçları uygulama, uygulama sonrası istenen etkiyi gözlemleme, herhangi bir yan etki olduğunda gerekli önlemleri alma, gerekli durumlarda sağlık kurumuna sevk etme, etik ilkelere ve yasal prosedürlere uyma gibi birçok uygulamayı bağımsız rolleri kapsamında yerine getirmektedir. Bu bağlamda ülkemizde de hemşirelerin bağımsız rolleri kapsamında homeopati uygulama yetkisine sahip olmaları için yönetmeliğin,
Avrupa ve Amerika' daki yasal prosedürler ve bu prosedürlerdeki hemşirelerin rol ve yetkileri açısından tekrar gözden geçirilmesi gerekmektedir.

\section{KAYNAKLAR}

Allaire, A. D., Moos, M., Wells, S. R. (2000). Complementary and alternative medicine in pregnancy: A survey of North Carolina nurse-midwives. Obstet Gynecol., 95(1): 19-23.

Baxter, J., Perrin, C. (2006). Homeopathy as a choice: The new holistic antenatal clinic. BJM., 14(12): 718-721.

Council for Homeopathic Certification (CHC) (2014). Examination and initial certification process, http://www.homeopathicdirectory.com/exam-process.html (10.04.2014).

Foxell, A. (2013). Homeopathy in labour and childbirth. Windsor Homeopathic Practice, Information Sheet 4, http://www.windsorhomeopathicpractice.co.uk/Homeopathy_in_Labour_Childbirth. pdf (10.12.2013).

Geraghty, B. (Ed.) (2002). Homeopathy for Midwives. 2nd ed., Churchill Livingstone Elsevier Science Limited, USA.

Hall, H. G., McKenna, L. G., Griffiths, D. L. (2012). Complementary and alternative medicine for induction of labour. Women Birth, 25(3): 142-148.

Heirs, M., Dean, M. E. (2007). Homeopathy for attention deficit/ hyperactivity disorder or hyperkinetic disorder. Cochrane Database Syst Rev., 2007(4): 1-29.

Homeopathic Nurses Association (HNA) (2014). Supporting nurses using homeopathy, http://www.nursehomeopaths.org/ (10.04.2014).

Homeopati Derneği (2014). Homeopati eğitimleri, http://homeopatidernegi.org/kursseminer/ (10.04.2014).

Huang, T., Shu, X., Huang, Y. S., Cheuk, D. K. L. (2011). Complementary and miscellaneous interventions for nocturnal enuresis in children. Cochrane Database Syst Rev., 2011(12): 1-68.

Idarius, B. (1999). The Homeopathic Childbirth Manual: A Practical Guide for Labor, Birth and The Immediate Postpartum Period. 2nd ed., Idarius Press, USA.

Jacobs, J., Jimenez, L. M., Gloyd, S. S., Gale, J., Crothers, D. (1994). Treatment of acute childhood diarrhoea with homeopathic medicine: A randomized clinical trial in Nicaragua. $J$ Pediatr., 93(5): 719-725.

Kassab, S., Cummings, M., Berkovitz, S., VanHaselen, R., Fisher, P. (2009). Homeopathic medicines for adverse effects of cancer treatments. Cochrane Database Syst Rev., 2009(2): 1-47.

Kömürcü, N., Berkiten- Ergin, A. (2008). Doğum ağrısının kontrolünde nonfarmakolojik yöntemler. Kömürcü, N., Berkiten- Ergin, A. (Eds.). Doğum Ağrısı ve Yönetimi. 1. basım, Bedray Basın Yayıncılık Ltd. Şti., İstanbul, 89-93. 
Martin, P. (2001). Homeopathic remedies for back labour and posterior presentation. Midwifery Today, 58, http://www.midwiferytoday.com/articles/homeopathic.asp (12.08.2012).

McCarney, R. W., Linde, K., Lasserson, T. J. (2004). Homeopathy for chronic asthma. Cochrane Database Syst Rev., 2004(1): CD000353

Merrell, W. C., Shalts, E. (2002). Homeopathy. Med Clin North Am., 86(1): 47-62.

Peckham, E. J., ve ark. (2013). Homeopathy for treatment of irritable bowel syndrome. Cochrane Database Syst Rev., 2013(11): 1-28.

Simpson, N., Roman, K. (2001). Complementary medicine use in children: Extent and reasons, A population-based study. Br J Gen Pract., 541(472): 914-916.

Smith, C. A. (2003). Homoeopathy for induction of labour. Cochrane Database Syst Rev., 2003(4):1-18.

Steen, M., Calvert, J. (2007). Self-administered homeopathy part two: A follow-up study. BJM., 15(6): 359-365.

T.C. Başbakanlık Mevzuatı Geliştirme ve Yayın Genel Müdürlüğü (2014). Geleneksel ve tamamlayıcı tıp uygulamaları yönetmeliği,
http://www.mevzuat.gov.tr/Metin.Aspx?MevzuatKod=7.5.20164 \&MevzuatIliski=0\&sourceXmlSearch=geleneksel (11.10.2016).

T.C. Sağlık Bakanlığı (2014). Homeopati sertifikalı eğitim program1 standartlar1, http://www.saglik.gov.tr/TR/dosya/1-100236/h/ homeopati-standart, -1.pdf (11.10.2016).

Tedesco, P., Cicchetti, J. (2001). Like cures like: Homeopathy. Am J Nurs., 101(9): 43-49.

The Accreditation Commission for Homeopathic Education in North America (ACHENA) (2014). The mission of ACHENA, http://www.achena.org/ (10.04.2014).

The European Committee for Homeopathy (ECH) (2014). The current regulatory status of homeopathic medicine in Europe, http://homeopathyeurope.org/regulatory-status/ (10.04.2014).

The Society of Homeopaths (2014). About homeopathy, http:// www.homeopathy-soh.org/about-homeopathy (10.04.2014).

Thomas, K. J., Coleman, P. (2004). Use of complementary or alternative medicine in a general population in Great Britain: Results from the national omnibus survey. J Public Health, 26(2): $152-157$. 
